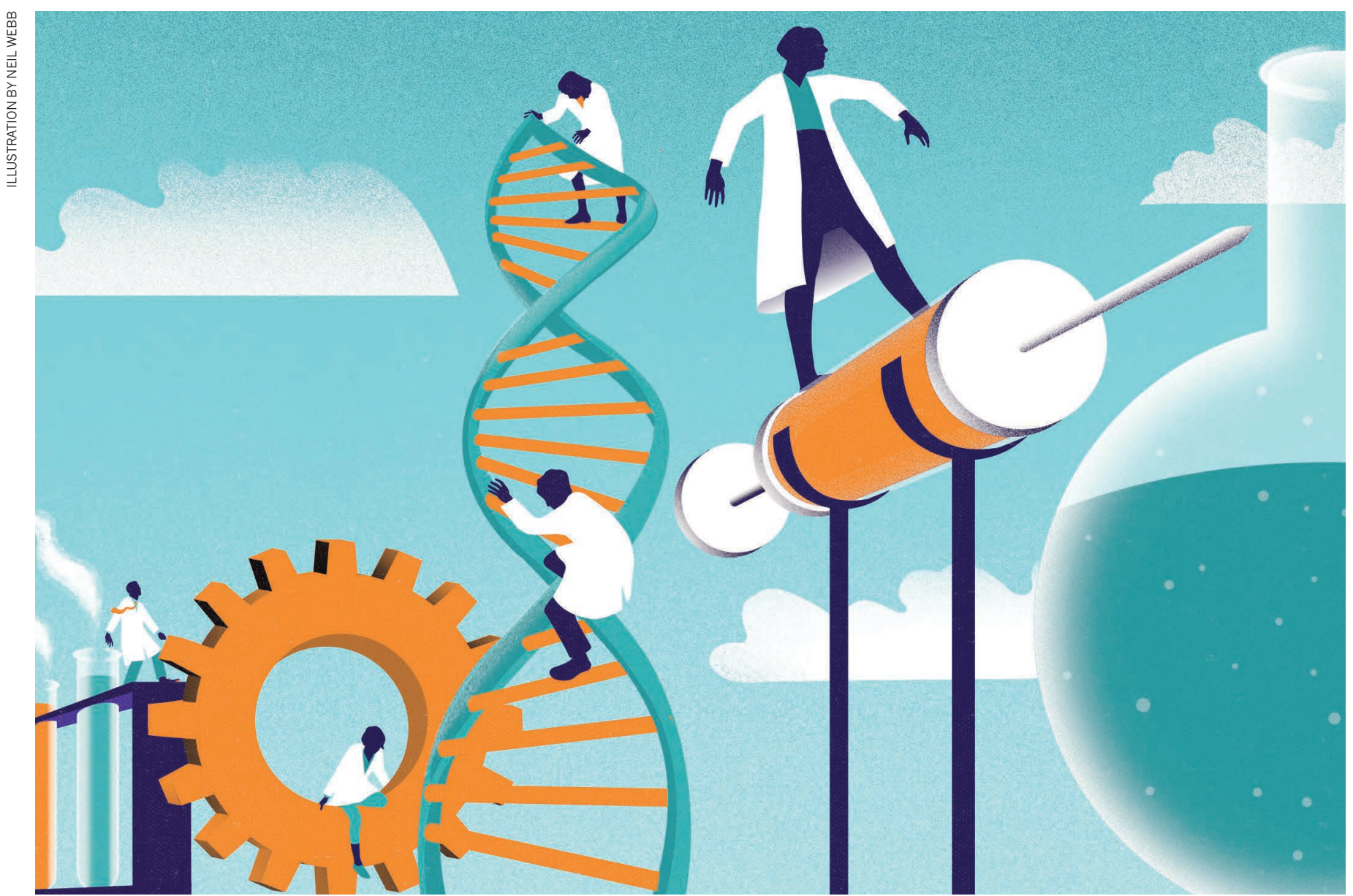

\title{
Beating the odds to secure a permanent contract
}

\section{Six early-career researchers offer advice on how to secure a permanent contract in academia, and then make the most of it.}

$\mathrm{R}$ esearchers hoping to start their own labs face long odds. A dramatic rise in the number of PhDs awarded each year has significantly reduced the chances of landing a permanent academic contract (see 'Long odds'). Data are sparse, but in the United States, for example, the number of available faculty biomedical positions has fallen since 1980 , whereas the number of people who have graduated with a $\mathrm{PhD}$ has increased by $60 \%$ (N. Ghaffarzadegan et al. Syst. Res. Behav. Sci. 23, 402-405; 2015).

The resulting competition for jobs breeds intense pressure that can take its toll on mental health. A paper published in Nature Biotechnology earlier this year reported that graduate students are six times more likely than the general population to experience depression or anxiety (T. M. Evans et al. Nature Biotechnol. 36, 282-284; 2018). And Nature's 2017 graduate survey found that $12 \%$ (of 5,700 respondents) had sought help for anxiety or depression caused by their $\mathrm{PhD}$ studies (see Nature 550, 549-552; 2017).

The usual advice for people seeking permanent academic positions is to get a good mentor, build up a solid network, publish plenty of papers and hope for a healthy dose of good luck. That advice, once intended to help potential new faculty members gain an advantage, are now minimum standards. A tighter job market demands some updated approaches.

Nature asked six young faculty members for their advice on how to prepare for a permanent position in academia, and how to make the most of one when it comes along.
VICTORIA RUIZ

\section{Design and follow a strategy}

Biologist at St Francis College, New York City.

Consider the type of academic you want to become: would you prefer to work in a research-focused institution, where most of your income is funded through external grants, or a teaching-focused institution, in which your salary is paid only if you teach alongside your research? Pick a postdoc position that aligns with that professional goal. 
$\checkmark$ If you are interested in teaching, you will need to demonstrate knowledge in pedagogy. Acquire a teaching certificate, a teaching assistantship or a part-time adjunct position on a fixed-term contract. If you already know you are interested in both teaching and performing research, you can apply for career-development awards that provide mentored postdoctoral research experience alongside teacher training.

Before beginning your job search, prepare statements about your research and your teaching. The research one should include details of your accomplishments and current work, as well as what you would like to achieve in the future. Distinguish your work from your mentor's because it will be difficult to obtain grants if your proposals are too similar to theirs. The teaching statement should discuss your academic mission and educational values, as well as provide an overall narrative of your tutoring style and process.

The search for an academic position is overwhelming, and can be discouraging. For me, however, that career path is one of the most satisfying. Following a strategic plan can help to make it happen.

KIRAN RAOSAHEB PATIL Work out your numbers

\section{Systems biologist at the European Molecular Biology Laboratory, Heidelberg, Germany.}

When struggling to find funding for my new lab in 2007, I decided to make life simpler for evaluators trying to compare my application with scores of others. I summarized my research in simple numbers: putting it in terms of publications, citations and the number of times someone requested software I had made.

Don't forget to include the less-obvious achievements. For example, when I was applying for my first faculty position, I had just finished my PhD and I didn't have too many publications. It was unlikely that I would stand out from my publication metrics alone, so I highlighted the number of different research areas in which my $\mathrm{PhD}$ work was being used.

Numbers can also act as motivators. Contrast "we aim to quantify a large number of metabolites" with "we aim to quantify 1,000 metabolites". The 1,000 not only gives a better idea of the project to the evaluator but also provides motivation - a sense of challenge and adventure - during the actual execution. And this motivation momentum is a fabulous thing to pass on to your team.

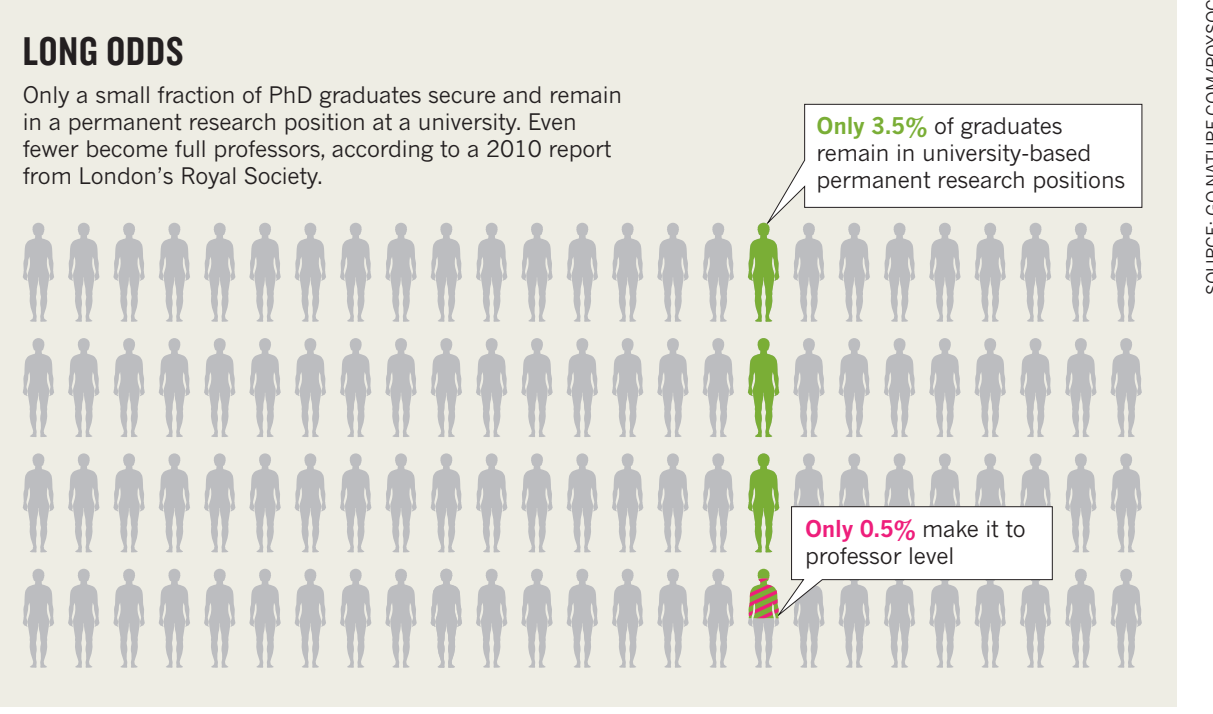

Not everything can be counted, of course, and there is more to research than numbers. But any fractional advantage can make a difference in the current competitive landscape. May the numbers be with you.

\section{AGNIESZKA WYKOWSKA Ride the wave of uncertainty}

Principal investigator and leader of the Social Cognition in Human-Robot Interaction laboratory, Italian Institute of Technology, Genova.

Academic life is a bit like surfing. A surfer's lifestyle provides excitement in pursuit of a never-ending summer and the perfect wave. A scientist's career can also be fuelled by fun, as we explore curiosity-driven questions and travel from conference to conference.

The parallels continue when one looks beyond the positive. Both surfing and academia require extremely hard work, a lifetime of training and commitment, and a huge dose of passion. Succeeding in both requires talent and dedication. But there is one more crucial skill that characterizes both academics and surfers: the ability to ride an uncertain wave. For scientists, the uncertainty lies in day-to-day practice as much as long-term planning.

In the day-to-day, scientists must learn to cope with the unpredictability of experimental results - whether they come out as expected or not. This might affect scientific output, such as publications. This, in turn, affects evaluations and grant proposals that determine the next job contract.

Those short-term events can make the future uncertain. A young academic needs to accept leaving comfort zones over and over again. They are like nomads - moving from country to country to continue with their science, uncertain of the form and frequency of communication with friends and family.

It can certainly be fun to move between countries and experience new job environments. It is a great experience to meet new people, work in different labs, learn about new cultures. But as time goes by, we also long for some stability and being able to plan more than two years ahead.

Rather than fighting the academic uncertainty, young scientists should try to embrace it. Stability is on the horizon as one becomes more senior. But to reach that goal, as a young academic, it is better to be ready to surf the scientific waves.

\section{MUIREANN IRISH Make peace with rejection}

\section{Cognitive neuroscientist at the University of Sydney, Australia.}

Because preparing a publication represents years of hard work, rejection often feels like a personal attack. In my field, journal acceptance rates hover around $20 \%$, and success rates for the two major national government funding bodies are no better. Statistically speaking, rejection is the norm.

I've developed methods to process rejection and learn from it. First, I give myself time. Some scientists - myself included will need to read the letter, get angry and then complain privately and bitterly about the reviewers until they feel better. After that, I do nothing for at least a week - I simply try to let the dust settle and wait to review the comments when things are calmer.

Rejection is not personal. Perhaps we 
misjudged the suitability of a paper for a particular journal, over-interpreted the novelty of our findings, or attempted to publish prematurely. There are similar reasons for rejections of funding applications.

Once the emotional reaction has subsided, discuss the review with your peers. In my lab group, we share our peer-review experiences, which helps to normalize the rejection. By openly sharing that my papers have been, and will continue to be, rejected, I hope to send a clear message to my students that rejection is part and parcel of academia and the world does not end when a paper is rejected.

Finally, never allow your self-worth to be determined by metrics. Academics by nature ascribe to high standards, and to be informed that your work is not good enough can feel like a personal failure. So many factors influence decisions on papers and funding applications, including timing, journal space, funding priorities and, sometimes, just pure luck.

Rejection is the norm, but it is not the end.

\section{KEIVAN STASSUN}

\section{Build more than good science}

\section{Physicist at Vanderbilt University,} Nashville, Tennessee.

Like all people, I think that scientists are at their best - both in and out of the lab when they feel that they are living lives of passion, purpose and meaning.

Of course, for many of us, the science itself is a passion. But there is also something to be said for having a mission to accomplish something bigger than publication, tenure or even research.

In my own life and career, I have made diversity and inclusion my extra calling. As a first-generation Mexican American from a very-low-income background, working to open doors for others who are underrepresented in science is deeply fulfilling. Even so, there are times when doing so goes against the advice of colleagues, who worry that I am doing that work in place of my science.

But I am convinced that having both focuses has made me a better, more fulfilled person as well as a better, more productive scientist.

While I built my lab I also created links between Vanderbilt and nearby Fisk University, a historically black university, through which more students from underrepresented groups could gain access to $\mathrm{PhD}$ courses. In a sense, I then had two opportunities - in my research and outside of it - to experience progress, and this doubled the reasons for being excited to go to work every day.

Passion and persistence together can lead to the greatest reward of all. Soon after I was awarded tenure, a mentor told me that while I had up to then been focused on building my reputation, now it was time to begin constructing my legacy. That advice has stayed with me. I can see even more clearly now how my two missions working together can make purpose and meaning - and ultimately legacy — possible.

\section{GOSIA TRYNKA Allow yourself time}

\section{Leader of immune-genomics group at the Wellcome Sanger Institute, Cambridge, UK.}

Last August, as I planned a seminar for $\mathrm{PhD}$ students, I panicked when I realized how little I needed to update my slides. My research had not progressed since the previous year's session. The next day, I shared my dismay with my PhD supervisor. "That's OK," she said, "give yourself five years to evaluate your performance."

She was right. It takes time to start a group, recruit scientists, set up experiments, analyse data and publish. There are many factors that need to come together before a group is productive.

For me, finding the right people was essential. Because I wanted to venture into large-scale genomics work on immune cells, I needed to build an interdisciplinary group that would combine expertise in immunology, epigenetics and population genetics. It takes time to find good people.

Once you've recruited, it takes more time to learn how to manage people and navigate a new host institution. Attend leadership courses and seek advice from your senior colleagues if necessary.

Finally, learn to manage expectations. Split tasks into smaller chunks, by setting intermediate goals and working towards achieving them. They will all add up to an overarching goal.

My group is now four years old. The pressure is still present, but I am more in control of it. I now have confidence that my group can design interesting projects, execute experiments, generate high-quality data and analyse them.

Evaluating myself a year from now still worries me, but when the time comes I'll be better prepared.

INTERVIEWS BY PAUL SMAGLIK

These interviews have been edited for clarity and length. 